\title{
NILAI SOSIAL DALAM NOVEL IBU, DOA YANG HILANG KARYA BAGAS D. BAWONO
}

\author{
Lian Pitasari $^{1}$, Nur Nisai Muslihah ${ }^{2}$, Dian Ramadan Lazuardi ${ }^{3}$ \\ Program Studi Pendidikan Bahasa dan Sastra Indonesia, STKIP-PGRI Lubuklinggau ${ }^{1,2,3}$ \\ dianramadan78@gmail.com ${ }^{3}$
}

Submit, 13-05-2018 Accepted, 10-06-2018 Publish, 14-16-2018

\begin{abstract}
ABSTRAK
Tujuan penelitian adalah untuk mendeskripsikan nilai sosial dalam novel $\mathrm{Ibu}$, Doa yang Hilang karya Bagas D. Bawono yang terdiri dari hakikat hidup manusia, hakikat karya manusia, hakikat kedudukan ruang dang waktu, hakikat hubungan manusia dengan alam dan hakikat hubungan manusia dengan sesama. Penelitian ini menggunakan metode kualitatif. Teknik pengumpulan data pada penelitian ini dengan teknik dokumentasi, teknik catat, dan teknik pengkodean, teknik penyeleksian, teknik dekskripsi, teknik kesimpulan dan teknik verifikasi data. Berdasarkan hasil analisis novel $\mathrm{Ibu}$, Doa yang Hilang karya Bagas D. Bawono yang telah dilakukan, menunjukkan bahwa hakikat hidup manusia terdapat 18 kutipan, hakikat karya manusia 8 kutipan, hakikat kedudukan ruang dan waktu 10 kutipan, hakikat hubungan manusia dengan alam 1 kutipan dan hakikat hubungan manusia dengan sesama 40 kutipan. Maka dapat disimpulkan bahwa dalam novel Ibu, Doa yang Hilang karya Bagas D. Bawono terkandung nilai sosial yang berkaitan dengan hakikat hidup manusia, hakikat karya manusia, hakikat kedudukan ruang dang waktu, hakikat hubungan manusia dengan alam, dan hakikat hubungan manusia dengan sesama.
\end{abstract}

Kata Kunci: Analisis, Sosial, dan Novel.

\section{ABSTRACT}

Target of research is to social value mendeskripsikan in novel Ibu, Doa yang Hilang of Bagas D. Bawono which consist of human life reality, human being masterpiece reality, reality domicile time dang space, human being relation reality with human being relation reality and nature with humanity. This research use method qualitative. Technique data collecting at this research with documentation technique, technique note, and code technique, selection technique, dekskripsi technique, conclusion technique and data verification technique. Pursuant to result of novel analysis Ibu, Doa yang Hilang of Bagas D. Bawono which have been done, indicating that human life reality there are 18 citation, human being masterpiece reality 8 citation, reality domicile time and space 10 citation, human being relation reality with nature 1 human being relation. Reality and citation with humanity 40 citation. Hence can be concluded that in novel Ibu, Doa yang Hilang of Bagas D. Bawono consist in social value related to human life reality, human being masterpiece reality, reality domicile time dang 
space, human being relation reality with nature, and human being relation reality with humanity.

Keyword: Analysis, Social, and Novel.

\section{PENDAHULUAN}

Sastra merupakan karya seni yang menyajikan nilai-nilai yang berkaitan kehidupan manusia dengan mengandung nilai keindahan. Karya sastra juga berfungsi dalam menarik pembaca untuk menyajikan realitas tertentu. Hal ini sejalan dengan pendapat Pradopo (2011), bahwa "Karya sastra merupakan karya seni yang mempergunakan bahasa sebagai mediumnya". Selanjutnya Emzir,dkk. (2015) mengungkapkan bahwa "karya sastra merupakan realitas kehidupan masyarakat secara kiasan. Artinya, karya sastra merupakan representasi cerminan seni dari masyarakat".

Karya sastra sangat melekat dengan kehidupan manusia karena di dalam kehidupan manusia banyak nilai-nilai untuk diungkapkan atau diaplikasikan. Karya sastra juga tidak bisa terlepas dari unsur masyarakat karena dari masyarakat pengarang bisa berimajinasi untuk menyalurkan isi pikirannya dalam bentuk tulisan sehingga tulisan yang digambarkan dalam kehidupan bisa disajikan secara luas dan mendalam. Menurut Murti (2017) nilai-nilai yang terkandung dalam karya sastra pada dasarnya mencerminkan realitas sosial yang memberikan pengaruh terhadap masyarakatnya. Sastra sebagai salah satu bentuk kebudayaan adalah seni yang menggambarkan kehidupan manusia. Wujud dari nilai budaya itu ada bahasa, sistem pengetahuan, sistem kemasyarakatan atau organisasi sosial, sistem peralatan hidup dan teknologi, sistem mata pencarian hidup, sistem religi, dan kesenian.

Beberapa pendapat di atas mengisyaratkan bahwa karya sastra adalah karya seni yang diciptakan oleh pengarang dengan menggunakan bahasa yang indah.Wujud karya sastra adalah puisi, drama, dan prosa. Menurut Nurgiyantoro (2012) prosa fiksi yaitu sebuah cerita yang terkandung untuk memberikan hiburan kepada pembaca dengan tujuan yang estetik seperti novel, roman, dan cerpen sedangkan prosa non fiksi yaitu sebuah cerita yang belum tentu terjadi kebenarannya contoh dongeng, legenda, sage dan mite. Salah satu bentuk karya fiksi yang sangat familiar di masyarakat berkaitan langsung dengan kehidupan sehari-hari yaitu novel. Menurut Sastromiharjo (2011) "Novel merupakan karangan sastra yang paling banyak digemari masyarakat". Banyak 
film layar lebar atau sinetron yang ide ceritanya diangkat dari novel. Novel juga merupakan karangan sastra yang menceritakan kehidupan sehari-sehari dengan berbagai konflik kehidupan masyarakat.

Novel best seller karangan Bagas D. Bawono merupakan novel yang menarik untuk diteliti. Diantaranya adalah novel yang berjudul Ibu, Doa yang Hilang, Novel ini berjumlah 260 halaman diterbitkan oleh Zettu. Hadirnya novel ini menyajikan tentang kepedulian dengan sesama manusia dengan menunjukkan adanya rasa syukur untuk bisa menolong sesama. Mengingat masyarakat Indonesia saat ini mulai merosotnya nilai-niai sosial yang sudah menjadi budaya Indonesia seperti hilangnya hidup berkasih sayang, persatuan, toleransi, gotong royong dan sebagainya. Hal ini juga diperkuat oleh Kosasih (2012) bahwa "Nilai-nilai sosial berkaitan dengan tata laku hubungan antara sesama manusia (kemasyarakatan)" Uniknya isi novel ini menceritakan kehidupan sehari-hari pengarang (yaitu mengenai "Ibu").

Peran seorang ibu pengarang sangat penting dalam mendidik anak-anaknya walaupun ibunya hanya single parents. Namun semangat juang dan kegigihannya dalam merawat serta memberi kasih sayang tak terkalahkan oleh apapun. Pekerjaan apa saja Ibu Bagas lakukan dari menjadi penjahit, merias pengantin, Guru TK, kursus jahit, buka usaha konveksi, jualan permen dan sebagainya. Salah satu prinsip Ibu Bagas yaitu hidup itu harus bermanfaat baik untuk diri sendiri dan juga orang lain. Dengan semangat karyanya beliau bisa mendirikan usaha Jamu tradisional, Dengan begitu bisa memberdayakan masyarakat sekitar untuk memberi lapangan pekerjaan. Hal inilah yang disebut dengan berkarya. Berkarya termasuk dalam salah satu nilai sosial yaitu hakikat karya manusia. Menurut Kluckhohn (dalam Sulaiman, 2012) "Karya itu untuk hidup, karya memberikan kedudukan atau kehormatan, karya memberikan gerak hidup untuk menambah karya lagi”".

Dari penelitian relevan yang dilakukan oleh Carina Aurelia dengan judul "Citra Perempuan dalam novel Ibu, Doa yang Hilang karya Bagas D. Bawono dan Rancangan pembelajarannya di Sekolah Menengah Atas (SMA)" membuat peneliti ingin meneliti pula novel Ibu, Doa yang Hilang karya Bagas D. Bawono dengan menitikberatkan pada aspek nilai sosial di dalamnya. Alasan dipilihnya dari segi nilai sosial karena pembaca selaku peneliti menemukan pembelajaran berharga dan manfaat yang banyak dalam novel ini karena karakter tokoh ibu yang tegas dalam mendidik dan mengajarkan cara 
bertingkah laku yang baik dalam hidup bermasyarakat sehingga membuat hidup pengarang bermanfaat untuk dirinya sendiri maupun orang lain.

\section{METODE PENELITIAN}

Penelitian ini menggunakan penelitian kualitatif dengan objek yang diteliti bersifat alamiah. Data dalam penelitian ini yaitu data yang berwujud kata-kata frase, kalimat, wacana dalam naskah novel dianalisis berdasarkan nilai sosial. Sedangkan data sekunder adalah data penunjang yang diperoleh dari buku-buku, artikel jurnal, dan latar belakang pengarang novel tersebut yang berkaitan dengan analisis nilai sosial novel Ibu, Doa yang Hilang karya dari Bagas D.Bawono. Sumber data dalam penelitian ini adalah Novel yang berjudul Ibu, Do'a yang Hilang berjumlah 260 halaman, novel ini juga cetakan ke 2 dari terbitan tahun 2015 penerbitnya Zettu Jalan Raya Munjul No.1 Cipayung Jakarta Timur. Teknik penggumpulan data yang dilakukan yaitu teknik dokumentasi, teknik catat, pengkodean, penyeleksian data, deskripsi, penarikan kesimpulan, dan verifikasi data. Sedangkan prosedur analisis data melalui langkahlangkah tahap deskripsi data, tahap klasifikasi data, tahap pengkodean, tahap analisis, tahap interpretasi data, tahap evaluasi, dan tahap kesimpulan.

\section{HASIL PENELITIAN}

Penelitian ini difokuskan pada analisis nilai sosial dalam novel $I b u$, Doa yang Hilang karya Bagas D. Bawono. Hasil penelitian ini menunjukkan bahwa nilai sosial mempunyai lima jenis yaitu hakikat hidup manusia berjumlah 18 data, hakikat karya manusia 8 data, hakikat kedudukan ruang dan waktu berjumlah 10 data, hakikat hubungan manusia dengan alam 1 data, dan hakikat hubungan manusia dengan sesama 40 data.

Berdasarkan hasil analisis hakikat hidup manusia isi novel Ibu, Doa yang Hilang karya Bagas D. Bawono terdapat 18 kutipan yaitu Sub bab Kalung sakti 001 di halaman 8 kutipan 002 di halaman 13, dan kutipan 003 di halaman 9. Bab. 4 Sang motivator kutipan 004 di halaman 26 dan 005 di halaman 27. Bab 5 Acrophobia 006 di halaman 37. Bab 7 Pembeli adalah Raja kutipan 007 di halaman 48. Bab. 9 Mandiri kutipan 008 di halaman 63. kutipan 009 di halaman 64 dan kutipan 010, 011, 012 di halaman 67. Bab 10 Merantau kutipan 013 di halaman 75. Bab. 11 Dongeng Ayah kutipan 014 di 
halaman 83 dan kutipan 015 di halaman 90. Bab Hadiah ulang tahun kutipan 016 di halaman 104. Bab 20 Berdiri sejak tahun 1938 kutipan 017 dihalaman 164. Bab. 23 Kreatif kutipan 018 di halaman 186

Nilai sosial hakikat karya manusia merupakan berkarya dan berkerja untuk mencapai suatu tujuan yang ingin dicapai untuk diri sendiri maupun untuk orang lain. Dalam isi novel Ibu, Doa yang Hilang karya Bagas D. Bawono terdapat 8 kutipan yaitu pada Sub Bab. Pembeli adalah raja kutipan 019 dihalaman 48. Sub Bab.11 Dongeng ayah kutipan 020 dihalaman 87. Bab.14 Kipas angin kutipan 021 dihalaman 110 dan kutipan 022 dihalaman 111. Bab. 16 Single parents kutipan 023 dihalaman 127. Bab. 20 Berdiri sejak 1938 kutipan 024 dihalaman 161. Bab. 21 Raga kutipan 025 dihalaman 167, dan Bab 24. Sub bab Kreatif kutipan 026 dihalaman 185.

Hakikat kedudukan ruang dan waktu merupakan nilai sosial yang menyangkut dengan waktu kejadian bisa diamati dari masa lampau, sekarang maupun yang akan datang. Berdasarkan hasil analisis ada 10 kutipan yang terdapat dalam isi novel $\mathrm{Ibu}$, Doa yang Hilang karya Bagas D. Bawono yaitu Sub Bab. 1 Saat sarapan pagi kutipan 027 di halaman 4. 2 Kalung sakti kutipan 028 di halaman 7. Bab. 3 Cerita tentang mesin singer tua kutipan 029 di halaman 17, kutipan 030 di halaman 28 dan kutipan 031 di halaman 30. Bab 6 Ikhlas kutipan 032 di halaman 43. Bab.11 Dongeng Ayah kutipan 033 di halaman 85 dan kutipan 034 di halaman 89. Bab 12 Uang saku kutipan 035 di halaman 93. dan bab 21 Raga kutipan 036 di halaman 169.

Nilai sosial hubungan manusia dengan alam yaitu manusia yang masih memerlukan alam untuk kebutuhannya karena manusia sebelum menyusaikan diri manusia harus kenal dahulu lingkungan sekitarnya. Pada dasarnya manusia akan kembali ke alam maka dari itu manusia harus saling menjaga. Berdasarkan hasil analisis ada 1 kutipan hakikat hubungan manusia dengan alam pada isi novel Ibu, Doa yang hilang karya Bagas D. Bawono yaitu Sub Bab. 11 Dongeng Ayah kutipan 037 di halaman 84 .

Hakikat hubungan manusia dengan sesama berarti manusia tidak bisa hidup sendiri, manusia masih membutuhkan orang lain untuk interaksi dan sebagainya karena manusia makhluk sosial yang hidup ditengah masyarakat. Berdasarkan hasil analisis pada novel Ibu, Doa yang Hilang karya Bagas D. Bawono terdapat 40 kutipan yaitu Sub Bab. 2 Kalung sakti kutipan 038 di halaman 10, kutipan 039 di halaman 11. Bab. 3 
Cerita tentang mesin singer tua kutipan 040 di halaman 21. Bab. 4 Sang motivator kutipan 041 di halaman 26, kutipan 042 dihalaman 27, kutipan 043 di halaman 28 dan kutipan 044 di halaman 28. Bab. 5 Acrophobia kutipan 045 dihalaman 33. Bab. 6 Ikhlas kutipan 046 di halaman 40 dan kutipan 047 di halaman 41. Bab. 7 Pembeli adalah raja kutipan kutipan 048 d ihalaman 47. kutipan 049 di halaman 50 dan kutipan 050 di halaman 51. Bab. 8 Televisi kutipan 051 dan 052 di halaman 56, kutipan 053 dan 054 di halaman 57, kutipan 055 di halaman 58 dan kutipan 056 di halaman 61. Bab. 9 Mandiri kutipan 057 di halaman 63 dan kutipan 058 di halaman 64 . Bab.10 Merantau kutipan 059 di halaman 71. Kutipan 060 di halaman 72, kutipan 061 di halaman 74, kutipan 062 dan 063 di halaman 75. Bab. 11 Dongeng ayah kutipan 064 di halaman 83-84, kutipan 065 di halaman 87. Bab. 12 Uang saku kutipan 066 di halaman 97. Bab 15 Permen sirsak kutipan 067 di halaman 117 dan kutipan 068 di halaman 118. Bab. 16 Single parents kutipan 069 di halaman 129 dan kutipan 070 di halaman 131. Bab. 17 beban ibu kutipan 071 di halaman 136 dan kutipan 072 di halaman 139. Bab. 18 Kegagalan kutipan 073 di halaman 144. Bab. 20 Berdiri sejak 1938 kutipan 074 di halaman 160. Bab. 22 Doa yang hilang kutipan 075 di halaman 175. Bab. 25 Dokter pribadi kutipan 076 di halaman 197. Bab. 29 kutipan 077 di halaman 232.

\section{PEMBAHASAN}

Penelitian ini difokuskan pada analisis nilai sosial dalam novel $\mathrm{Ibu}$, Doa yang Hilang karya Bagas D. Bawono. Berikut penjelasan hasil analisis data dapat dilihat di bawah ini :

\section{Hakikat Hidup Manusia}

Pada aspek nilai sosial yang pertama hakikat hidup manusia, yaitu hakikat yang masih saling berhubungan dengan prinsip dan karakter dalam diri manusia. Hal ini dapat dilihat sebagai berikut:

Tapi ibu ingin agar kamu berusaha mengalahkan ketakutanmu itu, le..., beliau menatap kedua mataku, dekat, hingga hembusan naspasnya mengaliri wajahku. (Hal. 8) (001)

Berdasarkan kutipan 001 dalam sub bab Kalung sakti, menunjukkan bahwa salah satu sikap Bagas yaitu ketakutan dalam perlombaan menyanyi, namun ibu Bagas meyakinkan bahwa Bagas dituntut bukan untuk menang namun untuk mengalahkan ketakutan yanga ada di dalam dirinya. Itulah salah satu cara ibu Bagas memotivasi 
Bagas untuk percaya diri terhadap dirinya sendiri. Hal ini sejalan dengan pendapat Kluckhohn (dalam Setiadi, 2009) menyatakan bahwa manusia adalah makhluk sosial atau makhluk bermasyarakat, selain itu juga diberikan yang berupa akal dan fikiran yang berkembang serta dapat dikembangkan.

Berawal dari keberanian ibu bagas bangga dengan Bagas karena bisa tampil semaksimal mungkin, Bagas menggunakan akal fikirannya menjadi lebih percaya diri tampil di depan umum, terlihat dalam kutipan 002 sub bab kalung sakti

"Ibu bangga melihat kamu berani, meskipun tidak menang. Lain kali kamu pasti akan lebih baik lagi.... Dan suatu saat kelak, kamu akan bisa menciptakan kalungmu sendiri agar kamu memiliki sebuah tekad dan keyakinan dalam memperjuangkan sesuatu”. (Hal. 13) (002)

Menurut Kluckhohn (dalam Setiadi, 2009) hidup itu baik sehingga membuat seseorang tersebut percaya diri dalam melakukan sesuatu karena di dalam fikirannya hidup itu selalu berjalan (dinamis). Kebanggan ibu Bagas terhadap Bagas yang mampu mengalahkan ketakutannya Bagas. Ibu Bagas selalu menyelipkan motivasi terhadap Bagas dalam memaknai hakikat kehidupan seperti yang dikatakannya sebuah tekad dan keyakinan dalam memperjuangkan sesuatu berarti setiap kehidupan harus mempunyai rasa perjuangan.

"Bukan hasilnya yang penting le..., akan tetapi perjuangannnyalah yang jauh lebih bernilai”. (Hal.14) (003)

Perjuanganlah dalam cakupan hakikat hidup manusia bukan dari keberhasilannya yang terpenting proses perjuangannya lah yang sangat bernilai. Luar biasa ibu Bagas dalam hal mendidik putra bungsuhnya dalam hal memaknai kehidupan salah satunya dengan membangun kepercayaan diri Bagas.

\section{Hakikat Karya Manusia}

Pada aspek nilai sosial yang kedua pada sub pembeli adalah raja ditemukan hakikat karya manusia yaitu setiap insan manusia pasti mempunyai karya karena setiap karya pasti dimulai dari kerja keras di dalamnya, harus juga didukung dengan ide yang kreatif pula demi mendapatkan uang ataupun suatu kedudukan.

Hal ini bisa dilihat sebagai berikut:

Jika sedang tak ada banyak pesanan jahitan dari pelanggan, ibu biasanya membuat pakaian-pakaian jadi, hasil kreasinya sendiri. Ada Gaun pesta, Kemeja, daster, baju anak hingga celana pendek. Kadang, kalau lagi bosan ibu 
akan ngulik kain-kain perca menjadi aneka barang. Bisa menjadi boneka, tas tangan, dompet hingga keset. Pokoknya, apa saja yang terlintas di pikiran ibu, ibu pasti bisa membuatnya. Beliau memang sangat kreatif. (Hal.48) (019)

Pernyataan diatas termasuk dalam hakikat karya manusia“"Ibu biasanya membuat pakaian-pakaian jadi, hasil kreasinya sendiri”. Karya sangat penting dalam suatu kehidupan dengan karya manusia akan berkembang dan mempunyai nilai untuk hidup yang lebih baik seperti yang terlintas difikiran ibu Bagas, pasti ia akan membuatnya seperti kemeja, Gaun pesta, daster dll. Beliau sangat kreatif.

Wayang kulit di luar kepala. Aku mempunyai koleksi lebih dari 20 tokoh wayang kulit yang dibuat oleh ayah dari karton bekas dengan kerangka bambu. Karton-karton ini dilukis dengan cat air dan spidol. Luar biasa, ayah sangat paham dan hapal detail-detail ukiran setiap tokoh pewayangan" (Hal.87) (020)

Kutipan sub bab Dongeng ayah ini menujukkan seorang ayah menunjukkan kreatifitasnya dengan cara memanfaatkan barang-barang yang tidak terpakai lagi seperti "karton bekas dengan kerangka" lalu disulap menjadi wayang kulit untuk digunakan mendongeng. Mendongeng merupakan kegiatan yang menyenangkan anak tetapi juga memberi suatu pelajaran melalui cerita yang dibawakannya. Walaupun Bagas dan kakaknya saat itu belum mengerti maksud tujuan cerita yang dibawakan oleh almarhum ayahnya kelak dewasa nanti mereka akan mengerti makna cerita wayang kulit yang sering dimainkan almarhum ayahnya.

\section{Hakikat Kedudukan Ruang dan Waktu}

Pada aspek nilai sosial yang ketiga pada sub bab pada saat sarapan pagi ditemukan hakikat kedudukan ruang dan waktu yaitu berbicara mengenai dimensi waktu yang terjadi dari dulu, sekarang maupun yang akan datang, memberi ruangan atau pengaharapan di dalam kehidupan ini.

Rupanya ibu sangat paham semua detail peristiwa penting diantara kami. Mulai dari ulang tahun, weton atau hari kelahiran menurut penanggalan jawa, hobi, hingga kebiasaanku di rumah setiap harinya. Dan hebatnya, ibu bisa memanfaatkan momen-momen itu untuk menjadikannya lebih memiliki arti, baik bagi kami sendiri, maupun bagi anak-anak kami.Kini beliau telah tiada, dan giliran kami menciptakan nilai-nilai positif dari setiap kejadian dalam keseharian.(Hal. 4) (027)

Pernyataan di atas menunjukkan“Ibunya yang telah tiada” semasa hidupnya, ibu Bagas selalu mengingatkan momen-momen yang dianggap penting dalam 
kehidupan Bagas dan keluarganya dari ulang tahun, weton, hoby hingga kebiasaan yang dilakukan. Hakikat kedudukan ruang dan waktu menjunjung tinggi adat istiadat dan norma sosial di dalam lingkungan masyarakat. Hal inilah yang ditunjukkan Bagas dan keluarganya untuk selalu mengamalkan nilai-nilai positif yang dilakukan ibunya selama ini walaupun ibunya sudah tiada.

Waktu aku duduk dikelas 3 SD, aku ditunjuk pak wid, Guru kesenianku untuk mengikuti lomba menyanyi. Saat itu aku masih tinggal di Surabaya dan bersekolah di SD Negeri Simpang 1 yang terletak di depan rumah dinas Gebernur Jawa Timur. (Hal. 7) (028)

Waktu menunujukkan kilas balik terhadap masa kecil Bagas yang pernah tinggal di Kota Surabaya sebelum akhirnya menetap dirumah kakek Bagas di Bojonegoro. Waktu itu ayah dan ibu Bagas masih lengakap saat ayah Bagas belum meninggal dunia. Semenjak ayahnya meninggal Bagas, kakak dan ibunya kembali ke Bojonegoro. Bojonegoro memang kecil namu disanalah tempat Bagas dan kakaknya menghabiskan waktu masa kecilnya yang penuh tantangan dan kekuatan seorang ibu.

Tiga puluh empat tahun lalu, sebuah mesin singer serbaguna.Bisa untuk membordir, membuat lubang kancing, dan membuat pola-pola pada aneka baju.(Hal. 17) (029)

Kutipan sub bab cerita tentang mesin singer tua ini menunjukkan perjalanan waktu yang panjang. Sudah seperempat abad mesin serba bisa ini menemani ibu Bagas dari membordir, membuat lubang kancing, dan membuat pola-pola pada aneka baju. Sangat luar biasa mengingat usia mesin tua itu "Tiga puluh empat tahun".Lewat mesin tua ini juga bisa membantu perekonomian keluarga Bagas, dimensi waktu memang membawa perubahan.

\section{Hakikat Hubungan Manusia dengan Alam}

Pada aspek nilai sosial keempat pada sub bab dongeng ayah ditemukan hakikat hubungan manusia dengan alam yaitu setiap kehidupan manusia pasti berkaitan pula dengan alam sekitarnya. Setiap manusia harus bisa menjaga dan merawat alam agar tidak rusak. Teruslah menciptakan keselaran dan sejalan dengan alam agar kelangsungan hidup tetap berlangsung. 
Ada tiga jenis dongeng yang biasa ayah sampaikan.Yang pertama adalah cerita mengenai bagaimana ayah dan rekan-rekannya bergerilya. Keluar masuk hutan dan perkampungan, mengatur strategi hingga kejadian-kejadian menegangkan seputar tawanan dan penyiksaan.(Hal.84) (037)

Pernyatan di atas "keluar masuk hutan" menceritakansewaktu ayah Bagas menjadi TNI dahulu ia sering bergerilya keluar masuk hutan dan perkampungan. Mengatur strategi hingga kejadian-kejadian menegangkan sputar tawanan dan penyiksaan. Kata-kata TNI tidak lepas dari alam dan sekitarnya karena banyak TNI angkatan darat sekarang yang menjaga perbatasan wilayah dengan bermukim dihutan dan kepolisian hutan ikut juga dalam penebangan kayu secara ilegal. Karena hutan dan alam tidak bisa dipisahkan dengan manusia karena saling membutuhkan.

Berdasarkan analisis hakikat hubungan manusia dengan alam diatas, dapat disimpulkan bahwa hakikat hubungan manusia dengan alam terdapat dalam sub bab novel Ibu, Doa yang Hilang karya Bagas D. Bawono berjumlah 1 kutipan.

\section{Hakikat Hubungan Manusia dengan Sesama}

Pada aspek nilai sosial kelima pada sub bab Kalung sakti ditemukan hakikat hubungan manusia dengan sesama yaitu hubungan manusia sesama manusia karena pada dasarnya manusia tidak bisa hidup sendiri. Manusia juga ingin bergaul dengan masyarakat. Manusia juga masih memerlukan orang lain untuk mencapai tujuan tertentu karena manusia makhluk sosial.

Jeng yang membordir baju pajenangan ya anakku iki lho..., sambil mengusap rambutku. Si pelanggan takjub melihat bordiran yang halus dan indah itu. "wahh.., pinternya .." pelanggan itu menatap bordiran anggrek di bajunya. Aku ikut mengamati. Luar biasa indah. Sebenarnya aku sendiri tidak percaya bahwa aku bisa membuat bordiran sebagus itu. (Hal. 21) (040)

Bagas terkejut melihat bordirannya semalaman sangat halus dan indah. Dalam hati hati Bagas waktu dia membordir baju pelanggan ibunya tadi malam melakukan tiga kali kesalahan saat membordir bunga dan daun anggrek terhadap baju pelanggan ibunya itu. Pelanggan ibu Bagas sangat memuji Bagas dengan hasil karyanya Bagas padahal Baju yang dibordir Bagas tersebut diulang border lagi oleh ibu Bagas buat pelanggan setianya. Begitulah cara ibu Bagas untuk percaya diri terhadap hubungan manusia dengan sesama. dengan begitu Bagas akan lebih giat lagi belajar dalam menjahit. Melalui kegiatan inilah salah satu wujud terjalinnya hubungan sesama manusia. 
Seringkali ibu memintaku untuk menjual permen ini disekolah, tapi aku malu dengan teman-teman. Sampai pada suatu hari, aku melihat ibu berbincangbincang dengan beberapa guru di ruang guru. Dan aku lihat, ibu menjual permen sirsaknya. Sejak saat itulah aku mulai berani menjual permen kesekolah dan menjual di lingkungan teman-teman dekatku saja. (Hal. 26) (041)

Anak seumuran Bagas waktu itu memang belum berani dan malu-malu untuk berjualan, mengingat umurnya masih 8 tahun. Namun dengan didikan ibunya dengan memberi contoh kepada Bagas melalui berjualan permen disekolah Bagas dengan menawarkan kepada guru membuat Bagas mempunyai keberanian diri dan membuang rasa malunya untuk berjualan permen di sekolah. Melalui hal ini terlihat bahwa Bagas telah berusaha untuk hidup mandiri.

"Gaji memang kecil, namun di sini ayah bisa membantu banyak orang”, kalimat itu yang sering diucapkan ayah. (Hal. 27) (042)

Kutipan ini menunujukkan bahwa membantu banyak orang berarti kehidupan manusia tersebut bermanfaat untuk orang-orang di sekitar. Ayah Bagas mengabdi dengan kepada negeri dengan bekerja di Dinas Sosial.

\section{SIMPULAN}

Berdasarkan hasil analisis data penelitian yang telah dilakukan, maka penulis menyimpulkan secara umum bahwa dalam novel Ibu, Doa yang Hilang karya Bagas D. Bawono mengandung nilai sosial yang berusaha untuk berjuang dalam menggapai kehidupan yang lebih baik ditengah masyarakat sekitar. Wujud dari perjuangan tidak terlepas oleh dukungan orang terdekat maupun lingkungan. Nilai sosial yang baik ada lima aspek pertama, yaitu hakikat hidup manusia dengan memegang teguh prinsip yang ada didalam diri sendiri serta mempunyai sikap yang santun, jujur dan apaadanya. Kedua, hakikat karya manusia yaitu adanya tekad dan kerja keras dalam segala hal yang ingin digapai. Ketiga, hakikat hidup kedudukan ruang dan waktu dengan adanya dimensi waktu akan membawa perubahan seperti kehidupan Bagas dari masa sulit berubah menjadi masa yang membahagiakan saat ini. Keempat, hakikat manusia dan alam, setiap manusia harus berdampingan terus dengan alam karena hidup akan kembali pula dengan alam. Kelima, hakikat hubungan manusia dengan sesama yaitu dari diri sendiri berhubungan dengan orang lain, seperti tokoh Bagas yang selalu memperioritas keluarganya dan pegawainya dalam menuju kehidupan yang lebih baik. 


\section{DAFTAR PUSTAKA}

Emzir dan Rohman. (2015). Teori dan Pengajaran Sastra. Jakarta: Rajawali Pers.

Kosasih. (2012). Dasar-Dasar Keterampilan Bersastra. Bandung: CV.Yrama Widya.

Murti, S., \& Maryani, S. (2017). Analisis Nilai Moral Novel Bulan Jingga dalam Kepala Karya M Fadjroel Rachman. Jurnal Kajian Bahasa, Sastra Dan Pengajaran (KIBASP), 1(1), 50-61. https://doi.org/https://doi.org/10.31539/kibasp.v1i1.93

Nurgiyantoro, Burhan. (2012). Teori Pengkajian Fiksi. Yogyakarta: Gadjah Mada University Press.

Pradopo, Rachmat Djoko. (2011). Beberapa Teori Sastra,Metode Kritik, dan Penerapannya. Yogyakarta: Pustaka Belajar.

Sastromiharjo. (2011). Bahasa dan Sastra Indonesia 2. Perpustakan Nasional

Setiady, M. Elly. (2006). Ilmu Sosial dan Budaya Dasar. Jakarta: Kencana Prenada Media Group

Sulaiman, Munandar. (2012). Ilmu Budaya Dasar. Bandung: PT Refika Aditama. 